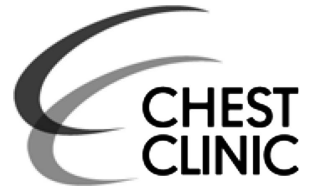

(6)

\section{OPEN ACCESS}

${ }^{1}$ Department of Public Health and Primary Care, Leiden University Medical Center, Leiden, The Netherlands 2Department of Epidemiology, University Medical Center Groningen, University of Groningen, Groningen, The Netherlands

${ }^{3}$ Department of Primary Community Care, Radboud University Nijmegen Medical Centre, Nijmegen,

The Netherlands

${ }^{4}$ Institute of Health Policy and Management/Institute of

Medical Technology Assessment, Erasmus University Rotterdam, Rotterdam, The Netherlands

\section{Correspondence to}

Annemarije L Kruis,

Department of Public Health and Primary Care, Leiden University Medical Center, PO Box 9600, Zone V-0-P

2300 RC Leiden,

The Netherlands:

a.l.kruis@lumc.nl

Received 9 December 2013 Accepted 11 December 2013 Published Online First 10 January 2014
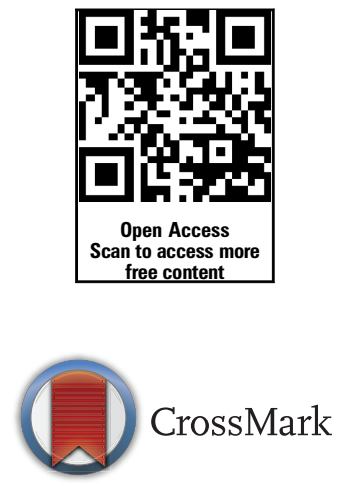

To cite: Kruis AL, Smidt $\mathrm{N}$, Assendelft WJJ, et al. Thorax 2014;69:1053-1055.

\title{
Cochrane corner: is integrated disease management for patients with COPD effective?
}

\author{
Annemarije L Kruis, ${ }^{1}$ Nynke Smidt, ${ }^{2}$ Willem J J Assendelft, ${ }^{1,3}$ Jacobijn Gussekloo, ${ }^{1}$ \\ Melinde R S Boland, ${ }^{4}$ Maureen Rutten-van Mölken, ${ }^{4}$ Niels H Chavannes ${ }^{1}$
}

\begin{abstract}
Abstract Patients with COPD experience respiratory symptoms, impairments of daily living and recurrent exacerbations. The aim of integrated disease management (IDM) is to establish a programme of different components of care (ie, self-management, exercise, nutrition) in which several healthcare providers (ie, nurses, general practitioners, physiotherapists, pulmonologists) collaborate to provide efficient and good quality of care. The aim of this Cochrane systematic review was to evaluate the effectiveness of IDM on quality of life, exercise tolerance and exacerbation related outcomes. Searches for all available evidence were carried out in various databases. Included randomised controlled trials (RCTs) consisted of interventions with multidisciplinary ( $\geq 2$ healthcare providers) and multitreatment ( $\geq 2$ components) IDM interventions with duration of at least 3 months. Two reviewers independently searched, assessed and extracted data of all RCTs. A total of 26 RCTs were included, involving 2997 patients from 11 different countries with a followup varying from 3 to 24 months. In all $68 \%$ of the patients were men, with a mean age of 68 years and a mean forced expiratory volume in $1 \mathrm{~s}\left(\mathrm{FEV}_{1}\right)$ predicted value of $44.3 \%$. Patients treated with an IDM programme improved significantly on quality of life scores and reported a clinically relevant improvement of $44 \mathrm{~m}$ on 6 min walking distance, compared to controls. Furthermore, the number of patients with $\geq 1$ respiratory related hospital admission reduced from 27 to 20 per 100 patients. Duration of hospitalisation decreased significantly by nearly 4 days.
\end{abstract}

\section{INTRODUCTION}

Patients with COPD show great variation in symptoms, limitations and quality of life, which often hampers good medical care. This calls for a multifaceted response, including different elements of care (eg, smoking cessation, physiotherapeutic reactivation, self-management, optimal medication adherence), delivered by various healthcare providers. In the last decade, the concept of integrated disease management (IDM) was introduced to improve quality and efficiency of care and to reduce healthcare costs. Earlier systematic reviews evaluating the effectiveness of IDM in patients with COPD precluded conclusive evidence, as they presented either limited pooled data, did not take into account differences in study design, or are currently out of date. Therefore, the objective of this Cochrane systematic review was to evaluate the effectiveness of IDM COPD programmes on the most relevant patient-reported outcomes: quality of life, exercise tolerance and exacerbation-related outcomes.

\section{METHODS}

Full details of the methods are reported in the original Cochrane publication. ${ }^{1}$ Briefly, we included randomised controlled trials (RCTs) published between 1990 and 2012, in which IDM was compared to a control intervention. IDM programmes had to consist of multidisciplinary ( $\geq 2$ healthcare providers) and multitreatment ( $\geq 2$ components) interventions with duration of at least 3 months until 12 months of follow-up. Primary outcome measures were (health-related) quality of life, exercise tolerance and exacerbation related outcomes. We identified citations using the highly sensitive Cochrane collaboration search strategy in all possible databases. Two reviewers independently searched, assessed and extracted relevant data of all RCTs. Results were pooled by applying random-effects modelling, using the mean change from baseline to end point for each group for continuous data; and the proportion of participants with each event for dichotomous data. We pooled data reported at 3 months for meta-analysis, as our predetermined inclusion criteria postulated a programme of at least 3 months duration (to ensure sufficient impact). If data at 3 months were unavailable, we analysed the data most closely measured after this time point. We performed subgroup analyses on type of healthcare setting (primary care vs secondary care), type of control group (usual care vs monodisciplinary treatment) and type of dominant component of the IDM programme (exercise vs self-management studies).

\section{RESULTS \\ Included studies}

Our search identified 6700 titles and abstracts, resulting in 4776 references after removal of duplicates. A total of 26 studies fulfilled the inclusion criteria, involving 2997 patients from 11 different countries. Overall, studies were of moderate to good quality. In all, $68 \%$ of the study participants were men, mean age 68 years, with mean forced expiratory volume in $1 \mathrm{~s}\left(\mathrm{FEV}_{1}\right)$ of $44 \%$ of predicted (range for study mean 28-66). The interventions were conducted in all types of healthcare settings: primary care (8 studies), secondary care (12 studies), tertiary care (1 study) and a combination of primary and secondary care (5 studies). The IDM programmes involved on average 3 
(range 2-7) healthcare providers and 4 (range 2-8) components of care.

\section{Main effects of the intervention}

The main results with a follow-up of 3-12 months are summarised in table 1. The St George Respiratory Questionnaire (SGRQ) was assessed in 13 studies $(n=1425)$. Pooled data showed a mean difference (MD) of -3.71 in favour of IDM (95\% CI -5.83 to $-1.59, \mathrm{p}<0.001)$, with a considerable amount of heterogeneity. After sensitivity analyses correcting for differences in study quality the direction or significance of the effect did not change. Pooled data on four studies $(n=160)$ using the chronic respiratory questionnaire (CRQ) demonstrated a clinically relevant and statistically significant result on all domains in favour of the IDM group: dyspnoea (MD 1.02; $95 \%$ CI 0.67 to $1.36, \mathrm{p}<0.0001$ ), fatigue (MD 0.82; 95\% CI 0.46 to $1.17, \mathrm{p}<0.0001$ ), emotion (MD $0.61 ; 95 \%$ CI 0.26 to $0.95, \mathrm{p}<0.0005)$ and mastery (MD $0.75 ; 95 \%$ CI 0.38 to 1.12 , $\mathrm{p}<0.0001)$. These results were homogeneous. We pooled data of 14 studies $(n=817)$ using the 6-min walking distance (6MWD). Patients treated with IDM improved their 6MWD statistically and clinically relevant by $43.86 \mathrm{~m}$ (95\% CI 21.83 to 65.89). There was considerable heterogeneity between the results of the studies. Sensitivity analyses correcting for studies with inadequate allocation concealment reduced heterogeneity, and the remaining MD was $15.15 \mathrm{~m}$, which was still statistically significant, however not clinically relevant. Pooled data from seven studies measuring respiratory related hospital admissions until 12 months of follow-up showed a statistically significant difference in favour of IDM (OR 0.68 ; 95\% CI 0.47 to 0.99 , $\mathrm{p}=0.04)$. On average, 20 out of 100 patients in the IDM group were admitted for respiratory related causes, compared to 27 out of 100 patients in the control group. We have estimated that, for 15 patients treated with an IDM programme over 3-12 months, 1 would avoid being admitted to hospital (number needed to treat $(\mathrm{NNT})=15(95 \%$ CI 9 to 505$)$ ). We pooled data from six studies $(n=741)$ reporting on the number of hospitalisation days. Patients treated with IDM were discharged nearly 4 days earlier from the hospital compared to controls (MD $-3.78 ; 95 \%$ CI -5.9 to $-1.7 ; \mathrm{p}<0.001)$. We found no statistically significant differences between groups on number of exacerbations, mean exacerbation rates, emergency department visits or differences in number of antibiotics or oral steroid courses.

In subgroup analyses, we found no differences between patients treated in primary or secondary care on quality of life or exercise tolerance. Subgroup analyses comparing different types of control groups showed the MDs between IDM and

Table 1 Summary of findings

\begin{tabular}{|c|c|c|c|c|c|c|}
\hline \multirow[b]{2}{*}{ Outcomes } & \multicolumn{2}{|c|}{ Illustrative comparative risks* $(95 \% \mathrm{CI})$} & \multirow{2}{*}{$\begin{array}{l}\text { Relative } \\
\text { effect } \\
(95 \% \mathrm{CI})\end{array}$} & \multirow{2}{*}{$\begin{array}{l}\text { No of } \\
\text { Participants } \\
\text { (studies) }\end{array}$} & \multirow{2}{*}{$\begin{array}{l}\text { Quality of } \\
\text { evidence } \\
\text { (GRADE) }\end{array}$} & \multirow[b]{2}{*}{ Comments } \\
\hline & $\begin{array}{l}\text { Assumed risk } \\
\text { (control) }\end{array}$ & $\begin{array}{l}\text { Corresponding risk } \\
\text { (disease management) }\end{array}$ & & & & \\
\hline $\begin{array}{l}\text { Disease specific } \\
\text { quality of life on the } \\
\text { SGRQ, total score } \\
\text { (follow-up: } \\
3-12 \text { months) }\end{array}$ & $\begin{array}{l}\text { The mean change in } \\
\text { the SGRQ (total } \\
\text { score) ranged from } \\
3.4 \text { lower to } 6.24 \\
\text { higher }\end{array}$ & $\begin{array}{l}\text { The mean SGRQ in the } \\
\text { intervention groups was } \mathbf{3 . 7 1} \\
\text { lower ( } 5.83 \text { to } 1.59 \text { lower). }\end{array}$ & $\begin{array}{l}\text { MD }-3.71 \\
(-5.83 \text { to } \\
-1.59)\end{array}$ & $\begin{array}{l}1425(13 \\
\text { studies) }\end{array}$ & Hight & $\begin{array}{l}\text { Minimal clinically important } \\
\text { difference }(M C I D)=-4 \text { points, lower } \\
\text { score means improvement }\end{array}$ \\
\hline $\begin{array}{l}\text { Disease specific } \\
\text { quality of life on the } \\
\text { CRQ dyspnoea domain } \\
\text { (follow-up: } \\
\text { 3-12 months) }\end{array}$ & $\begin{array}{l}\text { The mean change in } \\
\text { the CRQ (dyspnoea } \\
\text { domain) ranged } \\
\text { from } 0 \text { to } 0.2 \text { lower }\end{array}$ & $\begin{array}{l}\text { The mean CRQ dyspnoea } \\
\text { domain in the intervention } \\
\text { groups was } 1.02 \text { higher } \\
\text { ( } 0.67 \text { to } 1.36 \text { higher) }\end{array}$ & $\begin{array}{l}\text { MD } 1.02 \\
(0.68 \text { to } \\
1.36)\end{array}$ & 160 (4 studies) & Moderate $\ddagger$ & $\begin{array}{l}\text { MCID=0.5 points. Results on the } \\
\text { other domains of the CRQ (fatigue, } \\
\text { emotion, mastery) were also all } \\
\text { statistically and clinically relevant. }\end{array}$ \\
\hline $\begin{array}{l}\text { Functional exercise } \\
\text { capacity ( } 6 \text { min } \\
\text { walking distance } \\
\text { (6MWD)) (follow-up: } \\
3-12 \text { months) }\end{array}$ & $\begin{array}{l}\text { The mean change in } \\
\text { the } 6 \mathrm{MWD} \text { ranged } \\
\text { from } 38 \text { lower to } 36 \\
\text { higher }\end{array}$ & $\begin{array}{l}\text { The mean functional exercise } \\
\text { capacity in the intervention } \\
\text { groups was } 43.86 \text { higher } \\
\text { ( } 21.83 \text { to } 65.89 \text { higher) }\end{array}$ & $\begin{array}{l}\text { MD } 43.86 \\
(21.83 \text { to } \\
65.89)\end{array}$ & $\begin{array}{l}838(14 \\
\text { studies) }\end{array}$ & Moderate§ & $\begin{array}{l}\text { MCID=35 m. Sensitivity analysis } \\
\text { showed there was inconsistency in } \\
\text { the effect. After removing the low } \\
\text { quality studies, the MD was } \\
15.15 \mathrm{~m}(95 \% \mathrm{Cl} 6.37 \text { to } 23.93 \text {, } \\
\text { p }<0.001) \text {. }\end{array}$ \\
\hline $\begin{array}{l}\text { Respiratory related } \\
\text { hospital admissions } \\
\text { (follow-up: } \\
\text { 3-12 months) }\end{array}$ & $\begin{array}{l}27 \text { per } 100 \\
\text { patients }\end{array}$ & $\begin{array}{l}20 \text { per } 100 \text { patients ( } 15 \text { to } \\
27 \text { ) }\end{array}$ & $\begin{array}{l}\text { OR } 0.68 \\
(0.47 \text { to } \\
0.99)\end{array}$ & $\begin{array}{l}1470(7 \\
\text { studies) }\end{array}$ & High & \\
\hline $\begin{array}{l}\text { Number of hospital } \\
\text { days per patient (all } \\
\text { causes) (follow-up: } \\
3-12 \text { months) }\end{array}$ & $\begin{array}{l}\text { The mean change in } \\
\text { hospital days ranged } \\
\text { from } 1.6 \text { to } 11.9 \\
\text { higher }\end{array}$ & $\begin{array}{l}\text { The mean number of hospital } \\
\text { days per patient in the } \\
\text { intervention groups was } 3.78 \\
\text { lower ( } 5.9 \text { to } 1.67 \text { lower) }\end{array}$ & $\begin{array}{l}\text { MD }-3.78 \\
(-5.9 \text { to } \\
-1.67)\end{array}$ & 741 (6 studies) & High & \\
\hline
\end{tabular}

This table is based on a Cochrane Review published in the Cochrane Database of Systematic Reviews $2013^{1}$ (see http://www.thecochranelibrary.com for information).

Disease management compared to control for patients with COPD. Patient or population = patients with COPD. Settings: 8 studies in primary care, 12 studies in secondary care, 1 study in tertiary care, 5 studies each in primary and secondary care. Intervention: integrated disease management. Comparison: control (usual care).

GRADE Working Group grades of evidence are as follows. High quality: further research is very unlikely to change our confidence in the estimate of effect. Moderate quality: further research is likely to have an important impact on our confidence in the estimate of effect and may change the estimate. Low quality: further research is very likely to have an important impact on our confidence in the estimate of effect and is likely to change the estimate. Very low quality: we are very uncertain about the estimate.

${ }^{*}$ The basis for the assumed risk (eg, the median control group risk across studies) is provided in footnotes. The corresponding risk (and its $95 \% \mathrm{Cl}$ ) is based on the assumed risk in the comparison group and the relative effect of the intervention (and its $95 \% \mathrm{Cl}$ ).

tWe did not downgrade due to risk of bias, as studies contributing more than $2.7 \%$ to the meta-analysis had a low risk of bias. Sensitivity analysis on high-risk studies did not change the effect or significance of the effect.

¥We downgraded by one as there was considerable risk of bias in two studies on allocation concealment and two studies did not blind the outcome assessor.

§We downgraded by one as all included studies were of moderate to low quality. If we removed studies that scored high or unclear risk of bias on allocation concealment, the effect decreased to $15 \mathrm{~m}$.

$M D$, mean difference; CRQ, chronic respiratory questionnaire; SGRQ, St George Respiratory Questionnaire. 
controls were lower in studies using a monodisciplinary treatment as a control group, compared to studies using 'usual care' as a control group. Subgroup analyses focussing on the dominant component of the IDM programme showed that studies focusing mainly on exercise training provided a statistically significant greater improvement on exercise capacity and quality of life compared to studies focusing on self-management programmes.

\section{DISCUSSION}

This systematic review provides evidence for the efficacy of IDM COPD programmes of at least 3 months duration on quality of life and exercise tolerance until 12 months of follow-up. Furthermore, we demonstrated a reduction in respiratory related hospital admissions and hospital days when applying an IDM programme (NNT $=15$ to avoid 1 admission). This is of utmost importance, as hospitalisations contribute to the highest burden and costs in patients with COPD.

The main strength of our review is the high applicability of evidence, as we included 26 trials from all over the world, including interventions conducted in all types of healthcare settings and with inclusion of a broad COPD population. However, one should bear in mind that applicability may depend on the context of available healthcare resources. Several methodological strengths minimised the risk of bias in the review, including an a priori published protocol, including the definition of IDM, together with a comprehensive search strategy and assessment by two independent authors to identify all possible studies.

Limitations of this review include possible bias from poor reporting of data and a lack of publication of study protocols hindering investigation of so-called reporting bias. To correct for this, we contacted study authors to acquire additional data and we examined whether the outcome measures reported in the methods section were reported in the results section. Furthermore, we acknowledge the fact that controls substantially differs between countries and between healthcare settings. Our subgroup analyses suggest that the effects on the outcome measures could be less strong if controls received one component of IDM compared to patients receiving no treatment or usual care.

This review includes new trials that were not included in the earlier published systematic reviews analysing IDM in patients with COPD, and we were able to perform meta-analyses on all outcomes. Some studies included in this review were also evaluated in the Cochrane review addressing the effectiveness of pulmonary rehabilitation $^{2}$ or in the Cochrane review addressing the effectiveness of self-management. ${ }^{3}$ Subgroup analyses in our review demonstrated the largest effects on exercise capacity and quality of life in studies incorporating some form of exercise training, suggesting the necessity of including an exercise component in an IDM programme. This is in line with the results of those two reviews, where effects on exercise capacity and quality of life tended to be higher and clinically relevant in the pulmonary rehabilitation review, whereas in the selfmanagement review there was no effect on exercise capacity at all and the effect on quality of life was too small to be of clinical relevance. $^{2} 3$

We advise authors of future trials to report a proper description of the processes of randomisation, data collection and the details of the intervention prior to the start of the study in one of the trial registers. Finally, we advise authors to measure at least health-related quality of life, exercise tolerance or exacerbation related outcomes. We would endorse consensus on reporting of common outcomes, such as change from baseline. Long-term results on the effectiveness of IDM are still unclear, as only two studies published 2-year follow-up data, which demonstrated inconsistent results (data not shown). Therefore, we recommend future trials to include long-term follow-up data.

This article is based on a Cochrane Review published in the Cochrane Database of Systematic Reviews 2013, DOI: 10.1002/ 14651858.CD009437 (see http://www.thecochranelibrary.com for information). Cochrane Reviews are regularly updated as new evidence emerges and in response to feedback, and the Cochrane Database of Systematic Reviews should be consulted for the most recent version of the review.

Correction notice This article has been corrected since it was published Online First. The author affiliations have been amended.

Acknowledgements The authors would like to thank Liz Stovold for her help with the development of the search strategy. We would like to thank Emma Welsh and Julia Walters for their help with the development of the protocol and during editorial assistance and advice. We acknowledge the authors of the studies in providing additional data.

Contributors ALK, NHC and NS wrote the protocol. All authors contributed to and approved the protocol. ALK, NS and NHC selected the trials. ALK and NHC extracted data and assessed risk of bias. ALK was responsible for data management in Revman. All authors contributed and approved to the final version of the review.

Competing interests All authors, except NS are investigators of the RECODE trial, which investigates the cost effectiveness of integrated care in primary care patients with COPD in a cluster-randomised controlled trial in primary care. This trial is sponsored with a grant of ZonMW (Dutch governmental agency) and additional financial support by a Dutch healthcare insurer (Achmea). MR-vM reports grants from Dutch Asthma Foundation and the public/private partnership PICASSO for COPD, for conducting the INTERCOM trial, one of the studies included in the review. NHC is involved in several initiatives promoting education, developing software applications and providing e-health solutions that may be considered as potential conflict of interest.

Provenance and peer review Not commissioned; internally peer reviewed.

Open Access This is an Open Access article distributed in accordance with the Creative Commons Attribution Non Commercial (CC BY-NC 3.0) license, which permits others to distribute, remix, adapt, build upon this work non-commercially, and license their derivative works on different terms, provided the original work is properly cited and the use is non-commercial. See: http://creativecommons.org/ licenses/by-nc/3.0/

\section{REFERENCES}

1 Kruis AL, Smidt N, Assendelft WJ, et al. Integrated disease management interventions for patients with chronic obstructive pulmonary disease. Cochrane Database Syst Rev 2013;(10):CD009437.

2 Lacasse Y, Goldstein R, Lasserson TJ, et al. Pulmonary rehabilitation for chronic obstructive pulmonary disease. Cochrane Database Syst Rev 2006:CD003793.

3 Effing T, Monninkhof EM, van der Valk PD, et al. Self-management education for patients with chronic obstructive pulmonary disease. Cochrane Database Syst Rev 2007;CD002990 